\title{
All Hands on Deck-The Role of Chloroplasts, Endoplasmic Reticulum, and the Nucleus in Driving Plant Innate Immunity
}

\author{
Meenu S. Padmanabhan and S. P. Dinesh-Kumar \\ Department of Plant Biology and the Genome Center, College of Biological Sciences, University of California, Davis 95616, \\ U.S.A.
}

Submitted 14 May 2010. Accepted 10 June 2010.

\begin{abstract}
Plant innate immunity is mediated by cell membrane and intracellular immune receptors that function in distinct and overlapping cell-signaling pathways to activate defense responses. It is becoming increasingly evident that immune receptors rely on components from multiple organelles for the generation of appropriate defense responses. This review analyzes the defense-related functions of the chloroplast, nucleus, and endoplasmic reticulum (ER) during plant innate immunity. It details the role of the chloroplasts in synthesizing defense-specific second messengers and discusses the retrograde signal transduction pathways that exist between the chloroplast and nucleus. Because the activities of immune modulators are regulated, in part, by their subcellular localization, the review places special emphasis on the dynamics and nuclear-cytoplasmic transport of immune receptors and regulators and highlights the importance of this process in generating orderly events during an innate immune response. The review also covers the recently discovered contributions of the ER quality-control pathways in ensuring the signaling competency of cell surface immune receptors or immune regulators.
\end{abstract}

Every class of pathogen that infects animals can also infect humans. These pathogens include fungi, bacteria, viruses, nematodes, and insects. However, when animal systems have specialized mobile immune cells that exclusively detect and respond to pathogens, each plant cell must be individually equipped to do the same. At the molecular level, animal and plant cells utilize pattern-recognition receptors (PRR) to detect common pathogen factors and initiate an immune response. In plants, transmembrane cell surface PRR detect conserved molecular features shared by pathogens (Zipfel 2008, 2009). These may be cell wall components such as fungal chitin or oomycete $\beta$-glucan, fragments from bacterial flagellin, or abundant bacterial proteins such as an elongation factor (EF-Tu) (Gómez-Gómez and Boller 2000; Kunze et al. 2004; Miya et al. 2007). Because these signatures are present on a large number of pathogens, they are collectively termed pathogen-associated or microbe-associated molecular patterns (PAMPs or MAMPs, respectively).

The majority of the PRR that recognize PAMPs are receptorlike kinases (RLK), which have an extracellular leucine-rich

Corresponding author: S. P. Dinesh-Kumar; Telephone: +1.530.752.2205; Fax: +1.530.752.5410; E-mail: spdineshkumar@ucdavis.edu repeat (LRR) domain for PAMP recognition and an intracellular kinase domain for signal initiation. Two of the best studied RLK in plants are the flagellin-sensing 2 (FLS2) receptor and EF-Tu receptor (EFR) (Chinchilla et al. 2006; Zipfel et al. 2006). A smaller subset of PRR lack the kinase domain and are referred to as receptor-like proteins (RLP) (Postel and Kemmerling 2009). Once activated, the PRR initiate a series of metabolic processes that function to curtail pathogen growth. These include enhanced production of defense molecules, cell wall thickening, and release of systemic alarm signals that prime the rest of the plant. Together, these signals constitute PAMP-triggered immunity (PTI). Although PTI is often sufficient to prevent infection, many pathogens have evolved to produce specific effector molecules that function to dampen PTI. A second arm of the innate immune response-effectortriggered immunity (ETI) - has evolved to target these effectors.

ETI utilizes intracellular nucleotide-binding (NB)-LRR receptors that recognize a unique or small family of pathogen effector proteins. Some NB-LRR have an $\mathrm{N}$ terminal Toll interleukin 1 receptor (TIR) domain that shows homology to animal Toll interleukin 1 immune receptors. Others contain a coiled-coiled (CC) domain (Ausubel 2005; Jones and Dangl 2006). The NB-LRR are encoded by the resistance $(R)$ genes and, following recognition of the pathogen effector, they activate a specialized programmed cell death (PCD) pathway within infected cells that leads to tissue collapse and complete inhibition of pathogen growth. This specialized form of PCD is referred to as the hypersensitive response (HR) (Heath 2000). Some of the hallmarks of HR-PCD include activation of mitogen-activated protein kinase (MAPK) cascades, changes in intracellular calcium levels, increases in reactive oxygen species (ROS) accumulation, massive transcriptional reprogramming, and synthesis of defense compounds. Comparison of the molecular, biochemical, and physiological processes that occur during PTI and ETI shows that both of these pathways are intimately linked, and that it might be an increase in the amplitude of the signals during ETI that ultimately leads to HR (Tao et al 2003).

NB-LRR are versatile proteins that can recognize effectors using diverse strategies. In some cases, recognition occurs by direct ligand-receptor association, as is seen between the flax $R$ gene products and their cognate effector proteins from the flax rust (Ellis et al. 2007). In other cases, NB-LRR indirectly recognize effector-mediated modifications or perturbations of host proteins in order to activate ETI (Dangl and Jones 2001; Ellis et al. 2007; Caplan et al. 2008a). For instance the tobacco 
$\mathrm{N}$ immune receptor indirectly recognizes Tobacco mosaic virus (TMV) through alterations in the localization of the chloroplasttargeted $\mathrm{N}$ receptor interacting protein 1 (NRIP1) (Caplan et al. 2008b).

Although many proteins and signals controlling the immune response pathway have been identified, very little is known about their spatial distribution, subcellular localization, or dynamics during the immune response. Moreover, the role of subcellular organelles in defense is poorly understood. It was generally assumed that pathogen recognition occurred either at the plasma membrane or in the cytoplasm, and that this led to changes in nuclear gene transcription. Other organelles such as chloroplasts and the endoplasmic reticulum (ER) were thought to be passive players in this process, only occasionally serving as sites for pathogen replication. This view has recently begun to change with new studies showing that many subcellular organelles play a synergistic role in orchestrating a successful defense response. In this review, we focus on recent studies uncovering the role of the chloroplast, nucleus, and ER in driving innate immunity.

Role of the chloroplast in modulating innate immunity.

The role of the chloroplast extends far beyond its function as the main energy source for the plant cell. It is involved in the generation of defense signaling molecules such as ROS, nitric oxide (NO), salicylic acid (SA), and jasmonic acid (JA) (Takahashi and Asada 1988; Wildermuth et al. 2001; Torres et al. 2006; Wasternack 2007; Vlot et al. 2009). The chloroplast also serves as a sensor for detecting perturbations in the subcellular environment and actively communicates these signals to other organelles. Therefore, it is not surprising that many pathogen effectors target chloroplasts in order to dampen the release of chloroplast-derived stress signals. A number of
Pseudomonas syringae pv. tomato DC3000 effectors contain putative chloroplast targeted signal peptides (Guttman et al. 2002). The $P$. syringae pv. tomato DC3000 effector Hop1J was found to localize to the chloroplast, in which it contributes to a remodeling of the thylakoid membranes and suppression of SA production, leading to enhanced bacterial virulence (Jelenska et al. 2007). Hop U1, a mono-ADP-ribosyltransferase from $P$. syringae pv. tomato DC3000, suppresses innate immunity, in part, by targeting several chloroplast-localized RNA-binding proteins (Fu et al. 2007). As noted previously, the TMV viral replicase effector protein targets the chloroplast-localized NRIP1 leading to its relocalization (Caplan et al. 2008b). This change in localization of NRIP1 acts as the signal that leads to the $\mathrm{N}$ immune receptor activation and resultant HR-PCD.

There is also a strong correlation between HR induction and presence of functional chloroplasts. Arabidopsis variegation mutants infected with $P$. syringae pv. tomato DC3000 containing the effector AvrRpt 2 exhibited reduced HR in the white sectors that lacked chloroplasts (Genoud et al. 2002). Introduction of a cell-death-inducing bacterial elicitor, harpin, led to redistribution of chloroplasts from upper to the inner regions of the palisade cells within $5 \mathrm{~h}$ of effector protein introduction (Boccara et al. 2007). Harpin-containing cells also showed changes to the thylakoid membranes indicative of altered photosynthesis (Boccara et al. 2007). Thus, changes in chloroplast structure can be one of the earliest hallmarks of plant HRPCD. During N-mediated resistance to TMV, chloroplasts were observed to relocalize closer to the nucleus prior to the initiation of HR (J. Caplan, M. Padmanabhan, and S. P. DineshKumar, unpublished). Chloroplasts also redistribute themselves to be closer to the infection site in the moss Physcomitrella patens following infection by the oomycetes Pythium irregulare and $P$. debaryanum (Oliver et al. 2009). Although chloro-

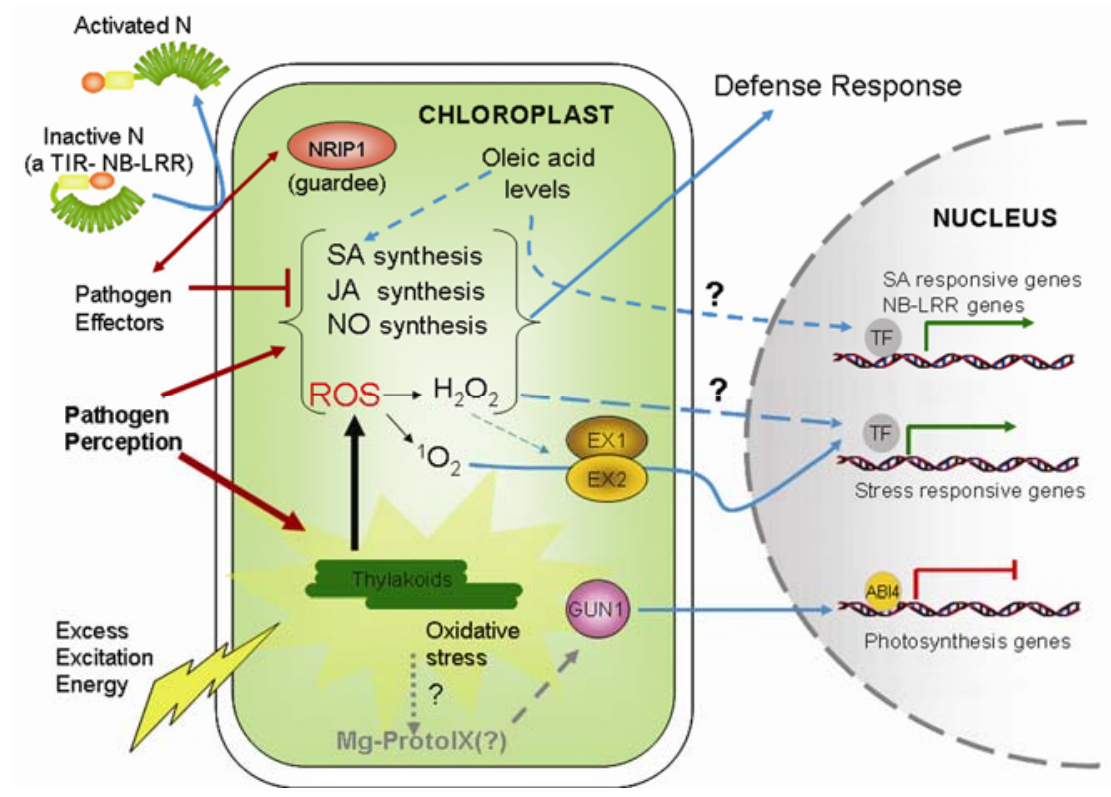

Fig. 1. Role of chloroplasts in regulating innate immunity. Following pathogen perception, chloroplasts synthesize important defense-signaling molecules such as salicylic acid (SA), jasmonic acid (JA), nitric oxide (NO), and reactive oxygen species (ROS). ROS can also be generated during photooxidative stress when the cell is unable to dissipate the excess excitation energy. ROS exist either as singlet oxygen $\left({ }^{1} \mathrm{O}_{2}\right)$ or hydrogen peroxide $\left(\mathrm{H}_{2} \mathrm{O}_{2}\right)$. Once generated, these molecules could initiate retrograde signaling from the chloroplast to regulate nuclear gene expression. ${ }^{1} \mathrm{O}_{2}$ signals through the executer 1 (EX1) and executer 2 (EX2) proteins to promote transcription of stress responsive genes. It is as yet unclear whether $\mathrm{H}_{2} \mathrm{O}_{2}$ could also activate the same pathway or regulate nuclear gene modulation thorough other pathways. Accumulation of Mg-ProtoIX, an intermediate of the chlorophyll synthesis, was initially speculated to be a retrograde signal. It was proposed to function through the genomes uncoupled (GUN1) protein to regulate the activity of the transcriptional repressor ABI4, leading to the suppression of chloroplast protein-encoding genes. Oleic acid levels in the chloroplast can also modulate defense response by regulating SA production and stimulating transcription of SA-responsive genes and a few nucleotide-binding leucine-rich repeat (NBLRR) genes. Several pathogen effectors target chloroplasts in order to suppress defense response activation. Chloroplast-localized proteins such as $\mathrm{N}$ receptor interacting protein 1 (NRIP1) also serve as recognition components (guardee) for some Toll interleukin 1 receptor NB-LRR such as N. Pathogenmediated changes in NRIP1 subcellular localization leads to $\mathrm{N}$ activation. 
plast rearrangement has been observed following light exposure and is thought to help regulate the photosynthetic activity of plant cells, it is not known why pathogen stress would induce such a change.

\section{Chloroplastic ROS and regulation of $\mathrm{HR}$.}

Rapid changes in ROS concentrations have been observed during biotic or abiotic stress responses. Once generated, quantitative differences in ROS concentrations can lead to initiation of PCD or, at lower levels, a phenomenon called systemic acquired resistance (SAR). During PCD, ROS can be cytotoxic to the host cell as well as the pathogen whereas, during SAR, it enhances production of defense molecules in distal parts of the plant, thus priming the host against a future attack. In general both processes occur in conjunction with the SA pathway, ethylene pathway, and signaling cascades that involve MAPK.

The enzymes required for ROS synthesis are diverse and exist in different subcellular compartments. The cytoplasmic and plasma-membrane-associated NADPH oxidases or respiratory burst oxidase homolog (Rboh) proteins are thought to contribute toward generation of the majority of the ROS involved in plant defense responses (Torres et al. 2002; Torres and Dangl 2005). However, ROS produced within the chloroplast has been shown to be important for immune response against TMV (Liu et al. 2007). In this case, pathogen-activated MAPK pathways specifically lead to ROS production in the chloroplasts, which then promotes HR-PCD induction (Liu et al. 2007). Furthermore, upregulation of chloroplastic proteins that promote the synthesis of $\mathrm{H}_{2} \mathrm{O}_{2}$ during the $\mathrm{N}$-mediated defense response to TMV has been observed (Caplan et al. 2009). A chloroplast-localized FtsH metalloprotease has also been shown to have a strong influence on the N-mediated HRPCD response (Seo et al. 2000). Following TMV infection, the FtsH transcript and protein levels are diminished. This decrease coincides with an inhibition of photosynthetic electron transport in the chloroplasts. FtsH proteins are found within the thylakoid membrane and are required for the repair of damaged components of photosystem II (Nixon et al. 2005). Therefore, it is possible that inhibition of the photosynthetic apparatus along with reduced ability to repair damaged components within the chloroplast could increase chloroplast ROS levels and positively regulate the HR-PCD response. In keeping with this hypothesis, an inverse correlation was observed between levels of FtsH proteins and intensity of HR-PCD. Chloroplast-derived ROS are also essential for the PCD response to nonhost pathogens like Xanthomonas campestris pv. vesicatoria. Transgenic tobacco plants that were specifically inhibited in their ability to produce chloroplast ROS showed a weaker cell death response following Xanthomonas sp. inoculation (Zurbriggen et al. 2009).

The identification of several lesion mimic mutants (lmm) has strengthened the role for chloroplast-derived ROS in initiating HR-PCD. These mutants show either spontaneous necrosis following exposure to intense light or spreading cell death (also called runaway HR) following pathogen infection. Many of these mutants have enhanced resistance to pathogens, suggesting heightened defense responses (Lorrain et al. 2003). Several of the $1 \mathrm{~mm}$ genes were found to be involved in chlorophyll biosynthesis or regulation of the chloroplast $(\mathrm{Hu}$ et al. 1998; Ishikawa et al. 2001; Pruinska et al. 2003, 2005; Mateo et al. 2004). It appears that $1 \mathrm{~mm}$ plants are unable to dissipate excess ROS produced during a cell-damaging event. This event could be triggered by abiotic stress like photo-oxidative damage or by biotic stress. Thus, the high levels of ROS result in aberrant or exaggerated HR-PCD induction. The $\operatorname{lmm}$ acd 2 is hypersensitive to light and biotic stress (Greenberg et al. 1994). Arabidopsis ACD2 encodes an enzyme that is involved in chlorophyll breakdown. In leaves, ACD2 may have a role in reducing oxidative stress in chloroplasts by breaking down photoreactive chlorophyll and, thus, negatively modulating PCD. Interestingly, the protein also has a PCD-inhibiting role in roots, which are generally devoid of chlorophyll (Yao and Greenberg 2006). Thus, it appears to have a PCD-inhibiting activity that is independent of its chlorophyll catabolism. ACD2 changes localization from the chloroplast and redistributes to the cytoplasm, chloroplast, and mitochondria during pathogen-induced stress. Mitochondrial-derived ROS production is essential for the PCD induced in $a c d 2$ mutants (Yao and Greenberg 2006). Together, these findings suggest that ACD2 could serve as a sensor for oxidative stress and functions in dampening the resultant PCD signals in multiple organelles.

\section{Raising the alarm: retrograde signaling during stress response.}

Considering the potentially damaging nature of ROS, cells have developed sensitive signaling cascades by which the nucleus can detect changes in chloroplast activity and respond to the stress signals. This phenomenon of communication from the chloroplast to the nucleus is termed "retrograde signaling." Photodamaged chloroplasts use retrograde signaling to downregulate nuclear-encoded photosynthesis-related gene expression (Oelmüller and Mohr 1986). Similarly, the ROS singlet oxygen $\left({ }^{1} \mathrm{O}_{2}\right)$ induces signaling from the chloroplast to initiate the nuclear transcription of stress-responsive genes, including many previously identified in the abscissic acid, JA, and SA pathways (op den Camp et al. 2003; Danon et al. 2005; Laloi et al. 2007; Lee et al. 2007).

There are many signals that can initiate retrograde signaling, including all forms of chloroplastic ROS (Fig. 1). Because ROS are generally unstable, it is unlikely that they leave the chloroplast. Instead, they may generate stable second messengers that can activate the signaling pathway. The exact nature of the messenger molecules exported from the chloroplast is, as yet, unknown. Some initial reports have suggested that $\mathrm{Mg}$ ProtoIX, an intermediate of tetrapyrole biosynthesis, may be the primary signal released from photodamaged chloroplasts. Mg-ProtoIX accumulates during chloroplast stress and correlates with reduced nuclear gene expression of photosynthesisrelated genes (Woodson and Chory 2008). However, two recent studies showed no significant correlation between the steady-state level of Mg-ProtoIX and nuclear target gene repression (Mochizuki et al. 2008; Moulin et al. 2008).

Genetic suppressor screens of conditional flu mutants that selectively produce high levels of singlet oxygen $\left({ }^{1} \mathrm{O}_{2}\right)$ have identified the chloroplast localized Executer1 (EX1) and Executer2 (EX2) proteins as mediators of ${ }^{1} \mathrm{O}_{2}$ responsive nuclear gene expression (Wagner et al. 2004; Lee et al. 2007). How the EX1 and EX2 proteins function in passing the signal to the nucleus is, as yet, unknown. Pathogenesis assays have not been carried out on the $f l u$, ex1, or ex2 single/double/triple mutants. However, microarray analysis of $f l u$ mutants have revealed that ${ }^{1} \mathrm{O}_{2}$ can initiate the transcription of a number of defense-related genes, including pathogenesis-related 1 (PR1), enhanced disease susceptibility (EDS1), members of the SA and JA signaling pathways, and members of the WRKY transcription factor family (Danon et al 2005). These findings link ${ }^{1} \mathrm{O}_{2}$ retrograde signaling in the activation of pathogen-induced cell death pathways. These studies also highlight the significant overlap in stress response pathways induced by photo-oxidative damage and biotic stress.

\section{Chloroplastic fatty acids in plant defense.}

Chloroplasts are the site of all fatty acid (FA) synthesis in plants. FA are integral components of the wax and cuticle that 
act as physical barriers for pathogens during basal defense (Weber 2002). FA serve as precursors for synthesis of the important defense molecule JA (Gfeller et al. 2010). Additionally, studies on FA metabolic pathways have revealed that $16 \mathrm{C}$ and 18C FA are important for effector-triggered defenses (Kachroo and Kachroo 2009). Increasing evidence suggests that FA-derived signals can modulate cross talk between different defensesignaling pathways. FA may have a role in initiating ROS production, because Arabidopsis fad7/fad8 mutants that are unable to synthesis linoleic acid (18:3) in chloroplast membranes also showed reduced accumulation of ROS following infection with the avirulent pathogen $P$. syringae pv. tomato DC3000 (avrRPM1) (Yaeno et al 2004). These mutants were susceptible to many avirulent bacterial strains and had decreased HRPCD (Yaeno et al. 2004). Levels of plastid-derived oleic acids (18:1) have been shown to regulate SA and JA pathways. Suppressor of SA insensitivity ( $s$ si) mutants deficient in the synthesis of oleic acid show spontaneous necrosis, elevated SA levels, and PR1 gene expression but are impaired in JA-mediated response (Kachroo et al. 2001; Kachroo et al. 2004, 2007; Jiang et al. 2009). Interestingly, low oleic acid levels initiate the nuclear transcription of not just SA pathway-responsive genes but also many $R$ genes in diverse plants such as Arabidopsis, soybean, and rice (Chandra-Shekara et al. 2007; Kachroo et al. 2008; Jiang et al. 2009). However, it is as yet not known if oleic acid levels are altered during an innate immune response. The mechanism by which oleic acid regulates nuclear gene expression is also unknown but hints at the possible role of chloroplast retrograde signaling in regulating targeted nuclear gene expression.

\section{Nuclear function in innate immune response.}

During active defense signaling, rapid and large-scale transcriptional changes following pathogen detection have been observed. Up to $20 \%$ of the genome can show significant changes in expression that reflect the cells' shift into a defensive mode (Maleck et al. 2000; Tao et al. 2003). Genes that are coregulated during defense are thought to be under the control of a limited but diverse set of key nuclear regulators. Many of these proteins are transcription factors such as the WRKY or TGA family members that are strictly nuclear in their localization. Others such as nonexpressor of PR gene 1 (NPR1), EDS1, and phytoalexin-deficient 4 (PAD4) may be present in multiple compartments but show dynamic, quantitative, and temporal changes in their localization that help to modulate their activity during defense. Recently, the NB-LRR immune receptors have been shown to have an active role in the nucleus.

\section{Nuclear role for NB-LRR.}

One of the most surprising and exciting findings in plant immune receptor studies is the recent discovery that some NBLRR immune receptors are localized in the nucleus, in which they can behave as cotranscriptional regulators (Deslandes et al. 2003; Burch-Smith et al. 2007; Shen et al. 2007; Wirthmueller et al. 2007; Liu and Coaker 2008; Caplan et al. 2008a; Cheng et al 2009). To date, five NB-LRR have been found to have nuclear or nucleocytoplasmic localization (Deslandes et al. 2003; Burch-Smith et al. 2007; Shen et al. 2007; Wirthmueller et al. 2007; Cheng et al 2009).

Mildew resistance locus A (MLA) proteins in barley are CCNB-LRR that recognize isolate-specific effectors from the powdery mildew fungus Blumeria graminis f. sp. hordei to provide race-specific resistance (Halterman et al. 2001; Zhou et al. 2001; Shen et al. 2003; Halterman and Wise 2004). Fluorescence microscopy and biochemical-fractionation-based approaches detected MLA proteins in both the cytoplasm and the nucleus (Shen et al. 2007). Upon pathogen infection, a modest increase in the nuclear pool of MLA protein was observed. Inhibition of MLA nuclear accumulation abolished HR-PCD, indicating a crucial role for the receptor within the nucleus. Furthermore, the nuclear-localized MLA proteins selectively associated with two transcriptional repressors belonging to the WRKY family (HvWRKY1 and HvWRKY2) (Shen et al 2007). This association was driven by the presence of the fungal elicitor, which indicates that only activated MLA can associate with and regulate the function of the WRKY proteins. In unchallenged leaves, these WRKY proteins function in suppressing the expression of PTI-related defense genes. Activated MLA proteins specifically relieve this suppression, leading to a spike in defense gene transcript levels and initiation of defense (Shen et al 2007) (Fig. 2).

The association of WRKY proteins and NB-LRR is also highlighted by studies carried out on the Arabidopsis resistant to Ralstonia solanacearum 1-R (RRS1-R) immune receptor. This is a unique TIR-NB-LRR that contains a C-terminal WRKY domain (Deslandes et al. 2002, 2003). RRS1-R confers broad-spectrum disease resistance against $R$. solanacearum expressing the effector Pop2. Both RRS1-R and Pop2 possess a nuclear localization signal (NLS); however, significant levels of RRS1-R were found in the nucleus only in the presence of the effector (Deslandes et al. 2003). It is hypothesized that activated RRS1-R can directly bind to the promoters of defense-responsive genes via the WRKY DNA-binding domain and regulate their transcription (Fig. 2). A mutation in this domain that abolishes DNA binding also leads to constitutive activation of several SA pathway genes, suggesting that the WRKY domain may function as a repressor (Noutoshi et al. 2005). In such a scenario, the bacterial effector would benefit from the presence of RRS1-R in the nucleus. To explain this apparent contradiction, Noutoshi and colleagues (2005) proposed that Pop2 could associate with and alter the WRKY domain of nuclear RRS1-R, which might activate the TIR-NBLRR region, leading to a signaling competent RRS1-R. Activated RRS1-R may have different functions from the inactive RRS-1R in unchallenged leaves. Another possibility is the modulation of RRS1-R activity by the Pop2 interacting protein responsive to dehydration 19 (RD19). RD19 is a droughtinducible cystein protease that was found to relocalize from mobile vacuole-associated vesicles to the nucleus in a Pop2dependent manner (Bernoux et al. 2008). Although RD19 was found to physically associate with Pop2 in the nucleus, such an association was not observed with RRS1-R. However, genetic analysis reveals that RD19 is required for the RRS1-R-mediated resistance. Interestingly, another member of a cysteine protease family in tomato has been shown to function in transcriptional activation, especially in response to a fungal elicitor (Matarasso et al. 2005). Thus, it is possible that nuclear RD19 could also function as a transcriptional activator and maybe even compete with RRS1-R for the same binding sites except, in this case, as an activator of gene expression (Bernoux et al. 2008).

The TIR-NB-LRR immune receptor $\mathrm{N}$ from tobacco is also present in both the cytoplasm and the nucleus (Burch-Smith et al. 2007). Although recognition of the viral effector protein (p50 domain of the 126-kDa viral replicase) occurred in the cytoplasm, the nuclear pool of $\mathrm{N}$ was essential for initiation of HR. Therefore, it would appear that, in the nucleus, activated $\mathrm{N}$ could promote transcriptional reprogramming that precedes HR-PCD. Though the nuclear accumulation of $\mathrm{N}$ during active immune response was not quantified, it has been previously shown that $\mathrm{N}$ protein levels increase in the presence of the $\mathrm{p} 50$ effector (Mestre and Baulcombe 2006).

Arabidopsis RPS4 is a TIR-NB-LRR gene that confers resistance to $P$. syringae pv. tomato expressing the AvrRps4 effec- 
tor. Unlike N and MLA, RPS4 contains a canonical NLS. Although a majority of RPS4 was observed in vesicles resembling endosomes, it was also detected in the nucleus (Wirthmueller et al. 2007). Mutation in the NLS abolished RPS4-mediated HR-PCD, suggesting an active role for the protein in the nucleus. N and RPS4 could associate with and regulate the activity of as-yet-unidentified transcription factors involved in mediating the defense response.

The suppressor of NPR1-1, constitutive (SNC1) is another TIR-NB-LRR that was recently shown to have nucleocytoplasmic localization (Cheng et al 2009; Zhu et al 2010). The snc11 is a gain-of-function mutant that encodes a constitutively active $\mathrm{R}$ protein which provides enhanced resistance to bacterial and oomycete pathogens (Li et al. 2001; Zhang et al. 2003). SNC1 contains an NLS and two nuclear export signals (NES) (Cheng et al. 2009). Biochemical fractionation studies along with transient expression of wild-type SNC1-green fluorescent protein (GFP) revealed the presence of the protein in the cytoplasm and nucleus (Cheng et al. 2009; Zhu et al. 2010). Interestingly, GFP fusions of gain-of-function SNC proteins showed enhanced nuclear accumulation and induced HR-PCD when transiently expressed in Nicotiana benthamiana (Zhu et al. 2010). Reducing the nuclear accumulation of some of these gain-of-function mutants by introducing a strong NES inhibited HR-PCD. These results suggest a strong correlation between levels of nuclear accumulation or activity of SNC1 protein and enhanced cell death or defense-signaling activities. The nuclear partners of SNC1 are yet to be identified.

Work on SNC1 also revealed a rather surprising effect of temperature in modifying nuclear accumulation of some NBLRR (Zhu et al. 2010). It has been well documented that NBLRR-mediated resistance is temperature sensitive and that, at elevated temperatures $\left(>28\right.$ or $\left.30^{\circ} \mathrm{C}\right)$, many NB-LRR proteins fail to activate resistance (Whitham et al. 1996; Hwang et al. 2000; Wang et al. 2009). It has previously been shown that the steady-state levels of some defense modulators are decreased at higher temperatures (Yang and Hua 2004). Microscopybased studies now suggest that, at nonpermissive temperatures, the nuclear localization of $\mathrm{N}$ and $\mathrm{SNC1}$ may be reduced (Zhu et al. 2010). This sensitivity appears to be intrinsic to the protein because point mutations within SNC1 can overcome the temperature sensitivity and restore nuclear localization to levels comparable with those seen at permissive temperatures. Quantitative measurements of nuclear protein levels have not been taken to see if the results complement the microscopybased data. The authors speculate that temperature could alter

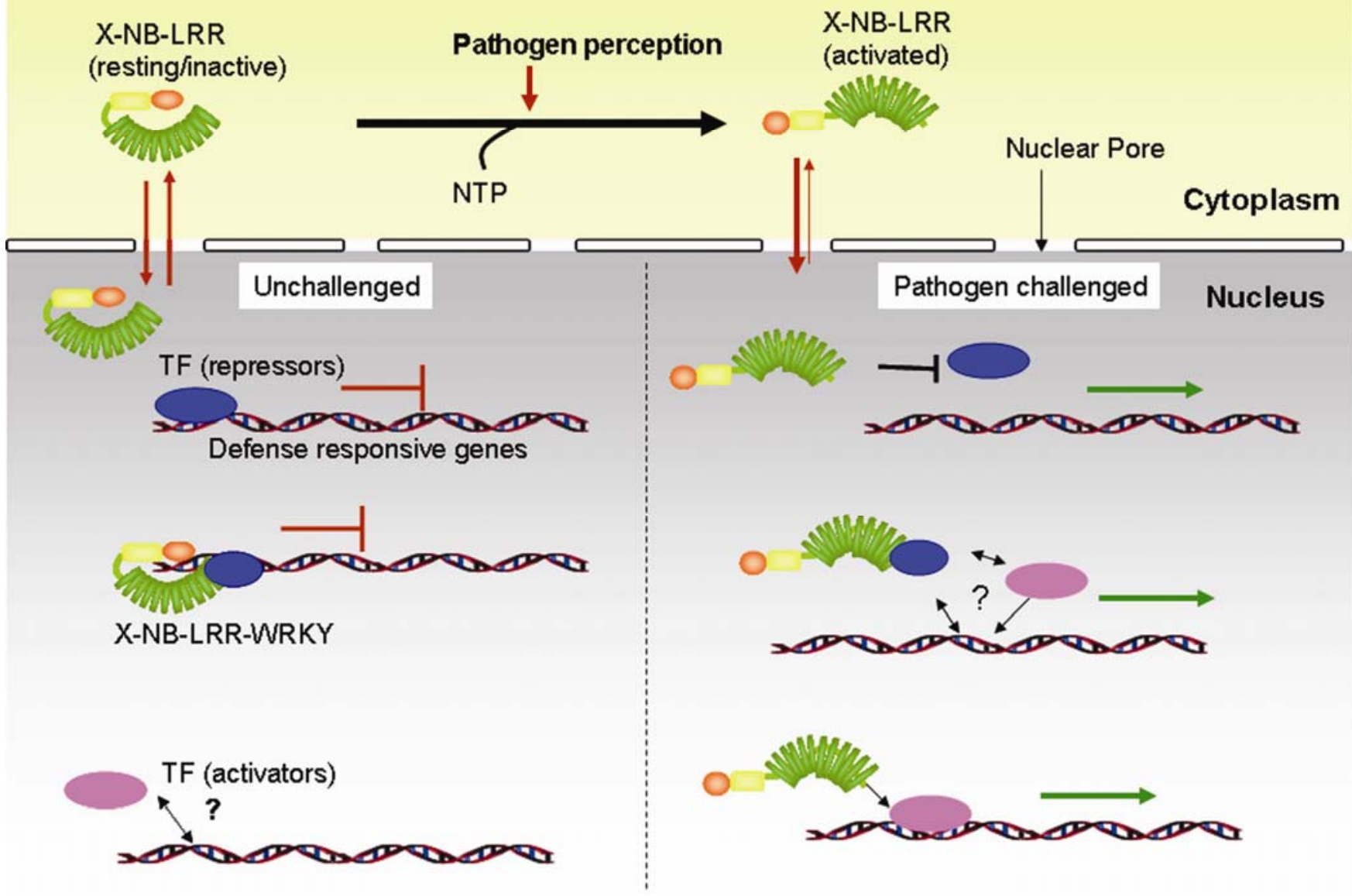

Fig. 2. Nucleocytoplasmic activities of nucleotide-binding leucine-rich repeats (NB-LRR). In the absence of a pathogen elicitor, X-NB-LRR such as N, RPS4, and mildew resistance locus A (MLA) are autorepressed and may continuously cycle between the cytoplasm and nucleus. Defense gene expression in these cells is suppressed either by transcriptional repressors (blue circles) present on the promoters of target genes or by the absence of activators (pink circles). Some NB-LRR such as resistant to Ralstonia solanacearum 1-R that contains the DNA-binding WRKY domain may directly function in repressing gene expression. Pathogen perception in the cytoplasm leads to a conformational change in the immune receptor, presumably following nucleiotide binding to the NB domain. Following activation, some immune receptors may show enhanced nuclear accumulation. Within the nucleus, some receptors (such as MLA) promote transcription by actively inhibiting transcriptional repressors. Others could recruit or activate as-yet-unknown transcriptional activators. NBLRR-WRKY proteins in the nucleus may undergo conformational changes that result in inactivation of its repressor domain or recruitment of unknown activators. All three scenarios culminate with transcriptional activation of defense-responsive genes. 
intramolecular interactions, thereby destabilizing nuclear import. Alternately, high temperatures may affect the strength of association of NB and LRR domains with some chaperones.

\section{Nuclear activities of immune modulators EDS1 and PAD4.}

EDS1 and its regulatory partner PAD4 serve as important modulators of both PTI and ET1 (Wiermer et al. 2005). A majority of TIR-NB-LRR require EDS1 and PAD4 to mediate defense signaling (Aarts et al. 1998; Feys et al. 2001). The two proteins associate with each other in healthy tissue, and this association appears to strengthen in the presence of an avirulent pathogen (Feys et al. 2001). EDS1 also associates with the nuclear senescence-associated gene 101 (SAG101) protein, and protein accumulation studies revealed that all three proteins have mutually stabilizing effects on their interacting partners (Feys et al. 2005). Co-immunoprecipitation assays and size-exclusion chromatography-based experiments suggest com- plex and dynamic associations between the three proteins (Feys et al. 2005) (Fig. 3B). EDS1 and PAD4 fused to fluorescent proteins were found to localize to the cytoplasm and nucleus while SAG101 was exclusively nuclear. It appears that, in healthy tissue, EDS1 can exist in several molecularly distinct complexes such as EDS1-EDS1 homodimers, an EDS1-PAD4 complex, or an EDS1-SAG101 complex (Feys et al 2005). Fluorescence resonance energy transfer (FRET)-based association assays suggest that the EDS1-EDS1 homodimers predominantly exist in the cytoplasm while the EDS1-SAG101 association occurs only in the nucleus. The EDS1-PAD4 complexes could exist in both compartments (Feys et al. 2005). Although the nature of these complexes in pathogen-infected cells have not been analyzed and the biochemical mode of action of these three proteins remains unknown, it is tempting to speculate that there would be dynamic changes to the activity and distribution of the complexes during the immune response.
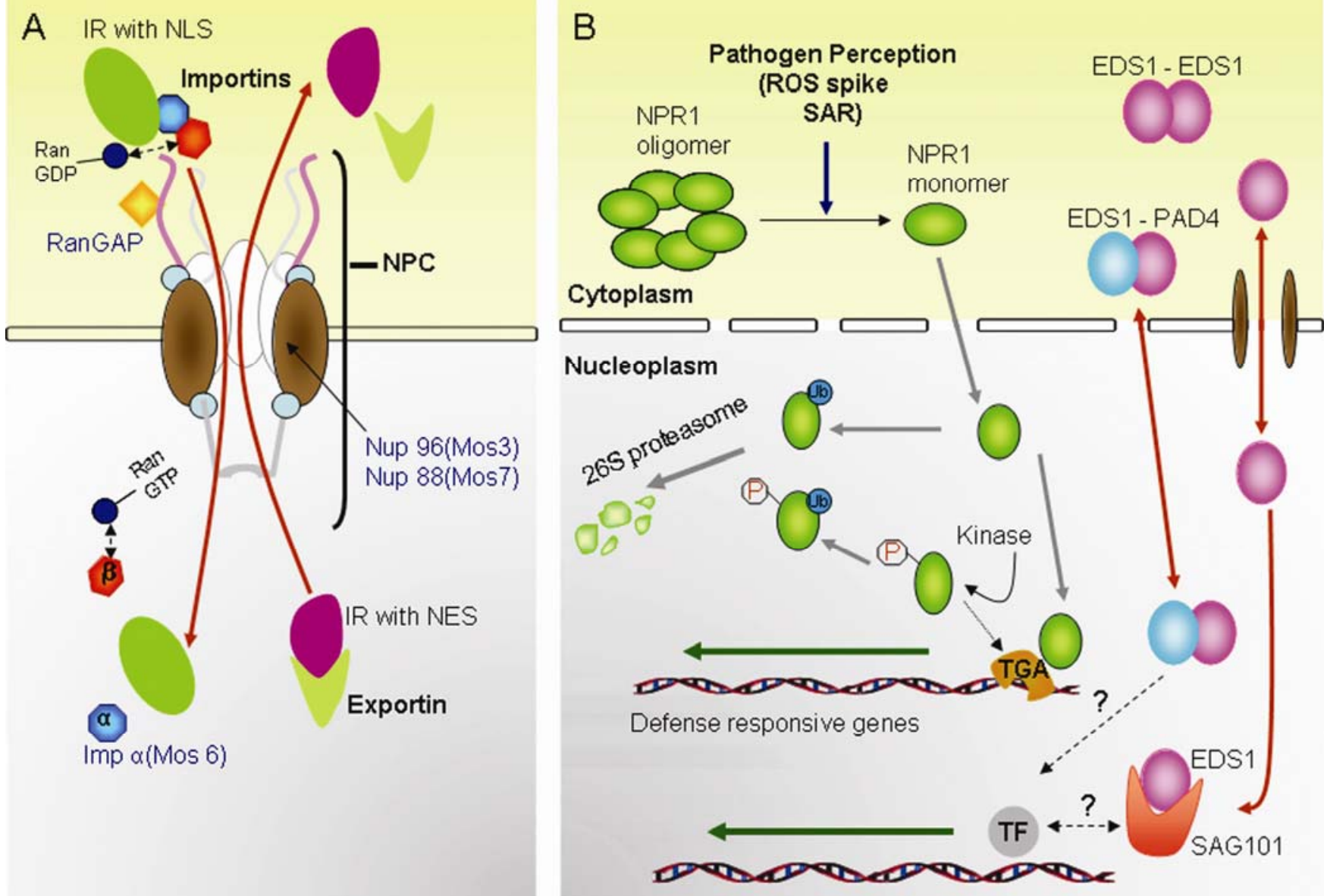

Fig. 3. Nucleocytoplasmic transport of immune receptors and modulators. A, In order to pass through the nuclear pore complex (NPC), immune receptors containing a nuclear localization signal (NLS) must associate with transport receptors such as importin $\alpha$ and importin $\beta$. Nucleoporins are important components of the NPC and facilitate movement of cargo-carrying importins across the pore. Transport is facilitated by a gradient of Ras-related nuclear (Ran)-GDP to Ran-GTP that exists between the cytoplasm and nucleoplasm. The RanGAP protein is a GTPase that is crucial to maintaining this gradient Mutations in importin $\alpha(m o s 6)$, Nup98 (mos3), or Nup88 (mos7) have been shown to impair nucleocytoplasmic transport of immune modulators, leading to suppression of defense responses. Nuclear export is facilitated by exportins that recognize the nuclear export signal (NES) on cargo proteins and move them across the NPC. B, In unchallenged cells, nonexpressor of pathogenesis-related gene 1 (NPR1) predominantly exists as inactive oligomers in the cytoplasm. Small levels of NPR1 monomers present in the nucleus are ubiquitinated and actively degraded via the 26S proteasome. Pathogen perception leads to a change in the redox potential within the cell, resulting in the reduction of NPR1 to active monomers. This leads to a large influx of monomeric NPR1 in the nucleus. Within the nucleus, NPR1 associates with TGA transcription factors to promote defense gene expression. Used NPR1 is phosphorylated and targeted for degradation, thereby allowing fresh NPR1 to be recruited to the promoters. Enhanced disease susceptibility (EDS1) activities are modulated by compartmentalization as well as by the association with phytoalexin-deficient 4 (PAD4) and senescence-associated gene 101 (SAG101). EDS1 can exist in a complex with PAD4 in both the cytoplasm and nucleus and is hypothesized to regulate gene transcription in the nucleus by an as-yet-unknown mechanism. EDS1 and the nuclear transcription factor SAG101 complex could also regulate the transcription of defense genes. EDS1 also exists as homodimers, primarily in the cytoplasm, though the activities of this complex are unknown. It is speculated that dynamic changes in the interaction affinities and concentrations of these complexes can modulate defense gene transcription. 
Nucleocytoplasmic transport

of NPR1 regulates its immune activity.

NPR1 is crucial for potentiating SA-mediated pathways and for the establishment of SAR. Its functions include activation of SA-driven defense gene transcription and modulation of SA synthesis with simultaneous inhibition of JA signaling pathway (Cao et al. 1997; Spoel et al. 2003; Zhang et al. 2010). The activity of NPR1 is regulated, in part, by its subcellular localization. NPR1 is present as stable oligomers in the cytoplasm of unchallenged leaves (Mou et al. 2003). Upon pathogen infection, the rise in SA levels changes the cell's reduction potential and promotes the partial conversion of the oligomer to active monomers (Mou et al. 2003). These monomers are recruited to the nucleus via a functional NLS in which they can associate with the TGA family of transcription factors to regulate expression of SA-responsive genes such as PRI and WRKY genes (Zhang et al. 1999; Kinkema et al. 2000; Mou et al. 2003; Dong 2004; Wang et al. 2006). Thus, the cytoplasmic/ nuclear ratio of NPR1 is used to fine tune the SA-mediated gene-expression pathway (Fig. 3B). Although nuclear NPR1 protein can activate SA-driven gene transcription, cytosolic NPR1 has a unique function in the suppression of the JA-responsive pathway by an as-yet-unknown mechanism (Spoel et al. 2003). Therefore, it appears that compartmentalization of NPR1 helps it to carry out multiple functions. Within the nucleus, NPR1 is under the regulation of the $26 \mathrm{~S}$ proteasome. The degradation of NPR1 prevents untimely defense gene activation and, surprisingly, was also found to be essential in stimulating NPR1-driven gene expression during an immune response (Spoel et al. 2009). The protein turnover also helps to maintain the cell's responsiveness to subsequent stimuli. The fact that NPR1 is under the control of multiple regulatory processes in distinct subcellular compartments is not surprising considering the broad-spectrum responses it can initiate. As discussed below, these results also highlight the use of the nuclear-cytoplasmic transport of regulators as a mechanism to generate orderly and timed events during an innate immune response.

\section{Role of nuclear pore complexes \\ in regulating immune protein transport.}

Nuclear transport of macromolecules occurs through the nuclear pore complex (NPC), which is composed of nucleoporins (Nup). Transport across the NPC occurs through the concerted action of import receptors (importin $\alpha$ and $\beta$ ), export receptors (exportins), and the GTPase activity of the Rasrelated nuclear (Ran) protein (Meier 2007). The NLS on cargo proteins is recognized and bound by importin $\alpha$ and importin $\beta$ promoting their active transport. The directionality of transport is maintained by the ratio of Ran-GDP (on the cytoplasmic side) to Ran-GTP (on the nuclear side). Considering the active transport of many NB-LRR into the nucleus, it is not surprising that mutants in the nuclear import-export machinery would show compromised immune response (Fig. 3B). One example of this is the requirement of a Ran GTPase-activating protein (RanGAP) for initiating Rx-mediated resistance to Potato virus $X$ (Sacco et al. 2007; Tameling and Baulcombe 2007). The fact that RanGAP associates with Rx suggests that it may facilitate the nuclear import or export of this CC-NB-LRR (Sacco et al. 2007; Tameling and Baulcombe 2007).

Genetic screens carried out on sncl-1 identified several modifiers of sncl (mos) mutants that dampened the constitutive defense signaling normally associated with the snc1-1 phenotype. A number of these mos mutants encode components involved in nucleocytoplasmic shuttling (Fig. 3A). MOS3, a homolog of the vertebrate Nup96, regulates NPC assembly and mRNA export and localizes to the nuclear envelope (Zhang and $\mathrm{Li} 2005$ ). The mos3 mutants were susceptible to a number of avirulent and virulent pathogens, indicating a role in regulating the export of components involved in both PTI and ETI. MOS7 is a homolog of animal Nup88 and also resides at the nuclear envelope (Cheng et al. 2009). Like mos 3 mutants, mos7-1 single-mutant plants are defective in PTI, ETI, and SAR. Nup88 in animal cells functions in dampening the export of nuclear proteins and it appears to have a similar function in plants as well. The mos $7-1$ plants show reduced nuclear accumulation of many defense-related proteins, including SNC1, NPR1, and EDS1. The mos6 mutant is disabled in activating immune responses and encodes an Arabidopsis importin $\alpha 3$ that was shown to modulated nuclear accumulation of SNC1 (Palma et al. 2005; Zhu et al. 2010)

$\mathrm{N}$ and MLA proteins that do not contain canonical NLS can still be efficiently imported into the nucleus (Burch-Smith et al. 2007; Shen et al. 2007). Their mechanism of nuclear transport remains a mystery. It is possible that transport occurs through the use of a noncanonical import-export machinery. If this were the case, then what domains or sequences in these proteins confer nuclear import? A combination of deletion analysis and confocal microscopy-based techniques can be used to identify the mode of transport and to study the dynamics of shuttling of NB-LRR during pathogen invasion. Identifying sequences or motifs that enable N or MLA nuclear localization may lead to the discovery of novel mechanisms of nuclear transport.

Alternatively, these proteins may use a "piggy back" route of transport in which a NLS-containing protein may be coopted as a carrier. It is also unclear whether these NB-LRR nucleocytoplasmic proteins undergo shuttling and, if so, whether kinetic shifts in this process occur during an active immune response. At least in the case of MLA, there appears to be an increase in nuclear import. It remains to be seen if this is, indeed, a general paradigm for nucleocytoplasmic NB-LRR.

The gene transcript levels of a number of chaperone proteins are known to be upregulated during the immune response (Azevedo et al. 2006). This is not surprising considering the crucial role for cytoplasmic chaperones like RAR1 (required for Mla12 resistance), HSP90 (heat-shock protein 90), and SGT1 (suppressor of the G2 allele of $s k p$ ) in the processing and folding of NB-LRR (Shirasu 2009). These chaperones cooperatively function in stabilizing and maintaining a recognitioncompetent state of NB-LRR proteins. Perhaps more intriguing was the finding that, during the $\mathrm{N}$-mediated immune response, a number of ER resident chaperons are also upregulated (Caplan et al. 2009). NPR1 also targets expression of some of the genes encoding ER resident chaperones (Wang et al. 2005). There is now increasing evidence to suggest that these ER-resident chaperones play a key role in both PTI and ETI.

\section{Role of ER chaperones in processing PRR.}

In eukaryotes, glycosylated membrane-localized proteins such as PRR are generally processed within the ER. Several mechanisms exist in the ER to ensure proper folding and maturation of these proteins before they are transported via the Golgi to the plasma membrane. Together, these processes form the ER quality-control pathway (ER-QC) (Anelli and Sitia 2008). Proteins that do not pass the stringent control are marked for degradation via ER-associated degradation (ERAD) pathway (Vembar and Brodsky 2008). Most of the functional analysis on ER-QC has been carried out in yeast and animal cells; however, it does appear that the plant homologs of ERQC proteins are conserved and have similar function (Vitale and Boston 2008; Pattison and Amtmann 2009).

ER-QC is made up of three distinct pathways that are characterized by the sequential and cooperative function of the en- 
zymes that carry out covalent modifications to clients and by the chaperone networks that assist in client protein folding and maturation. The first pathway relies on ER lectin-like chaperones while the second relies on an HSP70 chaperone complex containing luminal-binding protein $(\mathrm{BiP})$ for protein folding. The third pathway utilizes protein disulfide isomerase (PDI) and oxidorectases that introduce disulfide bonds between free thiol groups on nascent client proteins (Anelli and Sitia 2008). All three pathways have been directly or indirectly implicated in PRR maturation.

\section{The ER lectin chaperone complex regulates PRR folding.}

The ER lectin chaperone pathway is initiated by the oligosaccharyltransferase (OST) complex, which catalyses the $\mathrm{N}$ glycosylation of nascent proteins by transferring a glycan chain to the $\mathrm{N}$ terminus. The terminal glucose residues are then trimmed by glucosidase I (GI) and glucosidase II (GII) before the client is passed on to ER-resident lectin-like chaperons calnexin (CNX) and calreticulin (CRT), which initiate protein folding. Properly folded proteins are then transported through the endomembrane system to be released at their final target sites. Misfolded or partially folded proteins are recognized by the ER lumen sensor UDP-glucose:glycoprotein glucospyltransferase (UGGT). Recognition by UGGT enables the proteins to enter into another round of CNX- or CRT-assisted folding. If additional folding attempts are unsuccessful, the proteins will be targeted to ERAD (Williams 2006) (Fig. 4).

Plant PPR are glycosylated proteins and there is now evidence showing the requirement of components of the ER-QC N-glycosylation pathway in the processing of PRR associated with immune signaling. Several groups have shown the requirement of the ER-QC in the functioning of the Arabidopsis EFR protein (Li et al. 2009; Lu et al. 2009; Saijo et al. 2009). EFR recognizes the elf18 peptide fragment in the bacterial PAMP EFTu to initiate PTI (Zipfel et al. 2006). Two independent genetic screens identified mutants that were insensitive to elf18-induced physiological changes (Li et al. 2009; Lu et al. 2009; Saijo et al. 2009). Characterization of these mutants led to the discovery that many components of the ER resident $\mathrm{N}$-glycosylation pathway were crucial for the biogenesis and signaling competency of EFR. In the absence of an OST subunit, GII, CRT3, or UGGT, the steady-state levels of EFR were severely decreased, with most of the misfolded protein being targeted for degradation via ERAD (Saijo et al. 2009). Even in weak crt3 alleles that showed modest accumulation of the receptor, the signaling capabilities of EFR were compromised. Reductions in EFR abundance or signaling were also seen in Arabidopsis GII protein subunit (GII $\alpha$ and GII $\beta$ ) mutants ( $\mathrm{Lu}$ et al. 2009). This shows an involvement of the ER-QC proteins in modulating both steady-state levels of EFR and its post-recognition signaling. Interestingly, strong crt3 mutant alleles were more susceptible to pathogenic bacteria than the efr null mutants, which suggests that other defense-specific PRR may also be its clients (Li et al 2009). This appears to be the case, as described later on in the review.

\section{The ER BiP chaperone complex regulates PRR processing.}

A second ER-QC pathway involves the retention of misfolded proteins in the ER lumen by the HSP70 chaperone BiP. An ER lumen-localized Hsp40 co-chaperone (ERdj3B) recognizes the misfolded proteins and transfers them to BiP (Kleizen and Braakman 2004). BiP binding serves to stabilize folding intermediates and prevent their aggregation, and aids in subsequent protein folding and assembly attempts. The BiP pathway may occur in parallel with or in conjunction with the lectin chaperone pathway. The $\mathrm{BiP}$ pathway also regulates EFR folding with stromal-derived factor 2 (SDF2), a newly discovered member of the chaperone complex proving to be important in the folding process (Nekrasov et al. 2009). SDF2 localizes to the ER and associates with the BiP complex, in which it is proposed to act as a bridge between ERdj3B and BiP (Fig. 4A). In $s d f 2$ and $e r d j 3 b$ mutants, EFR protein levels are diminished. Moreover, most of the protein appears to be retained in the ER, presumably due to misfolding (Nekrasov et al. 2009). The $s d f 2$ plants are hypersusceptible to pathogenic bacteria and fungi, hinting at additional defense-related PRR as possible clients of SDF2. Therefore, EFR appears to be regulated by two ER-QC mechanisms that could act in concert. In tobacco, both CRT and $\mathrm{BiP}$ have been detected within a single complex (Crofts et al. 1998). Therefore, it is possible that EFR may be processed by a single complex containing CRT- and BiP-associated proteins.

The effect of BiP on PRR processing has to be considered in a case-by-case manner. Unlike EFR, knocking down BiP levels in rice had no effect on the signaling of the Xa21 PRR (Park et al. 2010). In fact, Xa21 appears to be inhibited in its localization in the presence of high levels of BiP. In this scenario, it is possible that increased levels of BiP led to aberrant association with $\mathrm{Xa} 21$ and inhibition of the processing and transport of the PRR to the PM. Alternatively, high levels of BiP may signal elevated ER stress which would lead to an inhibition of Xa21 processing.

Many of the ER-QC mutants such as crt3, uggt, erdj3B, and $s d f 2$ did not show pleiotrophic developmental defects (Nekrasov et al 2009; Saijo et al 2009). Thus, it appears that the clients for these proteins are exclusively related to the defense signaling pathways and not to general developmental pathways. This stands in contrast to animal ER-QC components, in which deletion of individual components can lead to embryonic lethality or cell death (Mesaeli et al. 1999; Anelli and Sitia 2008). Client-specific ER-QC members have not yet been identified in animals. Instead, an ER Hsp90 homolog gp96 appears to be a required for all tested animal Toll like receptors (Yang et al. 2007).

All of the ER-QC components identified thus far appear to specifically regulate the biogenesis of EFR and not FLS2. This is surprising because both of these proteins are glycosylated transmembrane PRR that belong to the same subfamily of LRR-receptor kinase (RK), detect PAMPS, and activate similar signaling pathways (Boller and Felix 2009). One proposed explanation is that FLS2 may be intrinsically more stable than EFR. FLS2 is evolutionarily more ancient than EFR and, therefore, may have developed higher protein stability, whereas EFR requires assistance from chaperones. NB-LRR are also dependent on chaperones because the diversification of their LRR sequences (as they co-evolve with the effectors) has compromised their structural stability. Therefore, association with chaperones is crucial in retaining them in a functionally active state. It is also possible that yet-to-be-identified ER-QC components may facilitate FLS2 folding and maturation.

\section{Involvement of ER derived chaperones in the transport of PRR to target membranes.}

Chitin elicitor receptor kinase 1 (CERK1) is a plant PRR that functions as the immune receptor for the fungal chitin (Miya et al. 2007). Work involving the rice CERK1 suggests that ER proteins assist not only in the maturation of this RLK but also form an integral component of a vesicle-trafficking pathway that transports CERK1 to the plasma membrane (Chen et al. 2010). The rice HSP90 and its co-chaperone Hop/Sti1 were found to associate with OsCERK1 via its transmembrane domain. Using live-cell imaging techniques, OsCERK1-GFP was observed in the ER and, following maturation, was transported to the PM via an ER to Golgi vesicle 
transport pathway. Hop/Sti1 is required for this transport because, in cells lacking Hop/Sti1, CERK1 appeared to be retained in the ER and chitin detection and subsequent PTI was significantly reduced. Hop/Sti1-Hsp90-CERK1-containing complexes were observed in the ER, endosomes, and the plasma membrane, confirming a role for these proteins in transport (Fig. 4B). Hop/Stil was also found to associate with OsFLS2, which suggests that the former may serve as a general facilitator of ER exit and transport. It has not yet been determined whether Hop/ Sti1 is constitutively present with its client PRR or whether it simply unloads the receptor to the plasma membrane.

\section{Role of ER chaperones in ETI.}

A number of ER resident chaperones are uniquely upregulated as an early step during $\mathrm{N}$ signaling response (Caplan et al. 2009). These include proteins such as BiP5, CRT2, and CRT3 and several PDI, which include ERp57 and P5. PDI are part of the third ER-QC pathway that is involved in disulphide bond formation in client proteins (Reddy et al. 1996). These proteins were found to be necessary for $\mathrm{N}$-mediated immunity because reductions in their transcript levels led to partial loss of resistance to TMV. This suggests a surprising role of components of the ER-QC proteins in NB-LRR mediated immunity.

CRT3 was found to modulate the steady-state levels of a newly identified $\mathrm{N}$-induced RK called induced receptor kinase (IRK) (Caplan et al.2009) (Fig. 4A). This IRK is the second defense-associated client protein identified for CRT3, EFR1 being the first. Thus, it is becoming increasingly apparent that the role of CRT3 in RK modulation may be more critical than other ER-QC members. One potentially fruitful area of research will be identifying additional clients of CRT and other ER chaperones that may be involved in modulating defensesignaling pathways.

The plasma-membrane-localized IRK is one of the first RLK known to play an important role in promoting HR-PCD initiated by an NB-LRR. It is obvious that it must act downstream of the pathogen recognition process because this step is carried out by cytosolic N. It is quite possible that $\mathrm{N}$ signaling activates the kinase domain of IRK and promotes downstream signaling. It is as yet unknown whether IRK is also activated by other ETI pathways. IRK may also have an ETI-independent role in recognition of an as-yet-unknown pathogen.
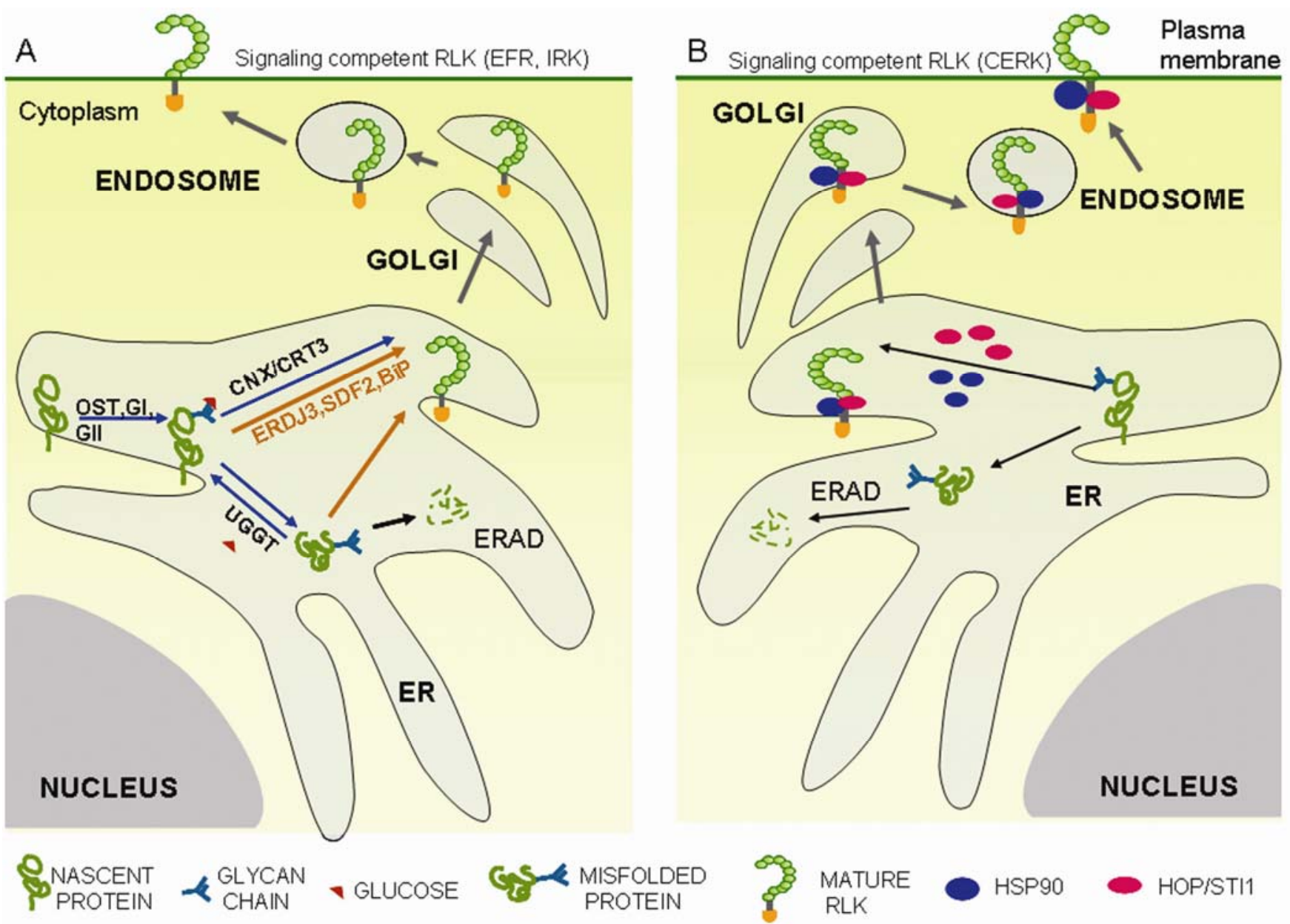

Fig. 4. Processing of receptor kinases by endoplasmic reticulum (ER)-resident chaperon complexes. A, Processing via the lectin and luminal-binding protein (BiP) chaperone complex: Nascent receptor kinases such as elongation factor Tu receptor (EFR) and induced receptor kinase (IRK) are processed through the lectin chaperone pathway (blue arrows). The receptor-like kinases (RLK) are glycosylated by the enzyme oligosaccharyltransferase (OST). Glucosidase I (GI) and gluciosidase II (GII) act in concert to trim terminal glucose moities before transferring the proteins to the luminal lectin chaperone proteins calnexin $(\mathrm{CNX})$ and calericulin (CRT). Proper folding leads to a signaling-competent, mature receptor kinase that is transported via the endosome pathway to the plasma membrane. Proteins that are misfolded are recognized by the folding sensor UDP-glucose-glycoprotein glucosyltransferase (UGGT) that reattaches a terminal glucose moity so that the protein can reenter the folding pathway. If additional attempts prove to be futile, the misfolded protein is degraded via the ER assisted degradation (ERAD) pathway. Some receptor kinases are also processed simultaneously via the BiP pathway (brown arrows). The heat-shock protein 70 (Hsp70) chaperone BiP along with the cochaperone ERdj3B and stromal-derived factor 2 (SDF2) cooperatively function in assisting the folding of both nascent and misfolded proteins. B, Processing and transport of pattern-recognition receptors (PRR) via the Hop/Sti1 chaperone complex: PRR such as chitin elicitor receptor kinase 1 (CERK1) are processed in the ER by Hsp90 and its cochaperone Hop/Sti1. After maturation, the chaperone proteins assist in the transportation of the PRR through the Golgi and endosomes to promote the integration of the PRR on the plasma membrane. 


\section{Role of ER resident $\mathrm{Ca}^{2+}$ pumps during an immune response.}

Cytosolic spikes in $\mathrm{Ca}^{2+}$ levels are one of the signatures associated with HR (Ma and Berkowitz 2007). $\mathrm{Ca}^{2+}$ is an important second messenger, and cellular calcium levels are kept under tight regulation by calcium transporters. These plant $\mathrm{Ca}^{2+}-$ ATPases are present in multiple membrane systems, including the ER (Geisler et al. 2000). Studies in N. benthamiana suggest that an ER resident calcium transporter $N b C A 1$ is selectively upregulated during the innate immune response and regulates HR-PCD induced by a number of effectors (Zhu et al. 2010). NbCA1 silencing alters the cytosolic and nuclear calcium signature by increasing the amplitude and duration of calcium spikes. As a result, HR-PCD is accelerated in these plants. Therefore, NbCA1 functions in modulating the magnitude of the calcium signal by controlling the rate of ER calcium efflux. Although the downstream decoders of the $\mathrm{Ca}^{2+}$ are not yet known, this study clearly shows that ER-resident $\mathrm{Ca}^{2+}$ pumps are important in sequestering the cytoplasmic $\mathrm{Ca}^{2+}$ released as part of the $\mathrm{Ca}^{2+}$ spike and, thus, regulate the severity of HRPCD.

\section{Conclusions.}

Considering the diverse molecular, biochemical, and physiological activities that drive the innate immune response, it is not surprising that the cell would organize these activities within distinct functional and spatial compartments. In one sense, this can be thought of as a simple division of labor, because complex tasks can be completed more efficiently when each organelle performs a smaller number of specialized tasks. Thus, receptor molecules are processed in the ER, which is the major site in the cell for protein folding and protein quality control. Similarly, the chloroplast, which serves as a biochemical factory for the cell, also synthesizes a majority of the defense metabolites. Some immune modulators can perform distinct activities in different subcellular compartments. Dynamic changes in their organellar accumulation can then be used to fine tune the cell's defense response. It is becoming increasingly obvious, however, that there is greater benefit to these organellar functions than a simple separation of jobs. In many instances an organelle can function as a sensor for the pathogenmediated perturbations, rapidly transmitting the alarm message through an intricate and robust communication pathway it has established with the nucleus. The nucleus is able to receive these diverse signals and co-ordinate appropriate changes in gene expression that then neutralize the pathogen while minimizing the associated fitness costs to the cell.

The fitness costs from accumulation of free radicals, accumulation of defense proteins or molecules, and reduced synthesis of photosynthetic transcripts or proteins, if left unchecked, could lead to decreased vegetative growth and seed set (Orgil et al. 2007).

Although this emerging picture of a synergistic role of organelles in immune responses is exciting, there is still only a patchwork of information available. There are only a handful of mechanistic links established between the different organelles, and the nature of the communication signals in not very well known. This is especially true for retrograde signaling from the chloroplast to the nucleus, in which many factors have been implicated but none have been proven as mediating cross talk. There is even less known about ER-nucleus cross talk during plant immunity. In animals, there is evidence that, during innate immunity, ER-synthesized transcription factors translocate into the nucleus and regulate response to ER stress (Richardson et al. 2010). Although similar proteins and pathways exist in plants, it is not yet clear whether they are similarly regulated during an immune response (Reiko 2009). Finally, the dynamic changes that some immune proteins undergo during their transport across different organelles also need to be thoroughly investigated.

Noninvasive and cutting-edge high-resolution microscopybased techniques can be used to image and record changes in organelles and organelle-associated protein or signaling molecule transport during innate immunity. Microscopic analysis using techniques such as fluorescence recovery after photobleaching, flourescence loss in photobleaching, fluorescence lifetime imaging, and correlative microscopy, along with biochemical and immunological protein quantification methods, can provide a great deal of insight into the dynamics of immune protein transport (Koster et al 2005; Dixit et al 2006). Novel genetic and biochemical screens can help unearth additional players mediating organelle cross talk. Considering the complexity already shown for these interactions, a systemsbiology approach would also be immensely helpful in identifying global changes in transcript and protein levels, and can be used to chart protein-protein and protein-nucleic acid interaction networks during innate immune responses.

\section{ACKNOWLEDGMENTS}

We thank A. Hayward for critical reading of the manuscript. Innate immunity work in the laboratory of S. P. Dinesh-Kumar is supported by grants from NIH-GM062625 and NSF.

\section{LITERATURE CITED}

Aarts, N., Metz, M., Holub, E., Staskawicz, B. J., Daniels, M. J., and Parker, J. E. 1998. Different requirements for EDS1 and NDR1 by disease resistance genes define at least two $R$ gene-mediated signaling pathways in Arabidopsis. Proc. Natl. Acad. Sci. U.S.A. 95:1030610311.

Anelli, T., and Sitia, R. 2008. Protein quality control in the early secretory pathway. EMBO (Eur. Mol. Biol. Organ.) J. 27:315.

Ausubel, F. M. 2005. Are innate immune signaling pathways in plants and animals conserved? Nat. Immunol. 6:973.

Azevedo, C., Betsuyaku, S., Peart, J., Takahashi, A., Noel, L., Sadanandom, A., Casais, C., Parker, J., and Shirasu, K. 2006. Role of SGT1 in resistance protein accumulation in plant immunity. EMBO (Eur. Mol. Biol. Organ.) J. 25:2007-2016.

Bernoux, M., Timmers, T., Jauneau, A., Briere, C., de Wit, P. J. G. M., Marco, Y., and Deslandes, L. 2008. RD19, an Arabidopsis cysteine protease required for RRS1-R-mediated resistance, is relocalized to the nucleus by the Ralstonia solanacearum PopP2 Effector. Plant Cell 20:2252-2264.

Boccara, M., Schwartz, W., Guiot, E., Vidal, G., Paepe, R. D., Dubois, A., and Boccara, A.-C. 2007. Early chloroplastic alterations analysed by optical coherence tomography during a harpin-induced hypersensitive response. Plant J. 50:338-346.

Boller, T., and Felix, G. 2009. A renaissance of elicitors: Perception of microbe-associated molecular patterns and danger signals by patternrecognition receptors. Annu. Rev. Plant Biol. 60:379-406.

Burch-Smith, T. M., Schiff, M., Caplan, J. L., Tsao, J., Czymmek, K., and Dinesh-Kumar, S. P. 2007. A novel role for the TIR domain in association with pathogen-derived elicitors. PLoS Biol. 5:e68. Published online.

Cao, H., Glazebrook, J., Clarke, J. D., Volko, S., and Dong, X. 1997. The Arabidopsis NPR1 gene that controls systemic acquired resistance encodes a novel protein containing ankyrin repeats. Cell 88:57.

Caplan, J., Padmanabhan, M., and Dinesh-Kumar, S.P. 2008a. Plant NBLRR immune receptors: From recognition to transcriptional reprogramming. Cell Host Microbe 3:126-135.

Caplan, J. L., Mamillapalli, P., Burch-Smith, T. M., Czymmek, K., and Dinesh-Kumar, S. P. 2008b. Chloroplastic protein NRIP1 mediates innate immune receptor recognition of a viral effector. Cell 132:449-462.

Caplan, J. L., Zhu, X., Mamillapalli, P., Marathe, R., Anandalakshmi, R. and Dinesh-Kumar, S. P. 2009. Induced ER chaperones regulate a receptor-like kinase to mediate antiviral innate immune response in plants. Cell Host Microbe 6:457-469.

Chandra-Shekara, A. C., Venugopal, S. C., Barman, S. R., Kachroo, A., and Kachroo, P. 2007. Plastidial fatty acid levels regulate resistance gene-dependent defense signaling in Arabidopsis. Proc. Natl. Acad. Sci. U.S.A. 104:7277-7282. 
Chen, L., Hamada, S., Fujiwara, M., Zhu, T., Thao, N. P., Wong, H. L., Krishna, P., Ueda, T., Kaku, H., Shibuya, N., Kawasaki, T., and Shimamoto, K. 2010. The Hop/Sti1-Hsp90 chaperone complex facilitates the maturation and transport of a PAMP receptor in rice innate immunity. Cell Host Microbe 7:185-196.

Cheng, Y. T., Germain, H., Wiermer, M., Bi, D., Xu, F., Garcia, A. V., Wirthmueller, L., Despres, C., Parker, J. E., Zhang, Y., and Li, X. 2009. Nuclear pore complex component MOS7/Nup88 is required for innate immunity and nuclear accumulation of defense regulators in Arabidopsis. Plant Cell 21:2503-2516.

Chinchilla, D., Bauer, Z., Regenass, M., Boller, T., and Felix, G. 2006. The Arabidopsis receptor kinase FLS2b binds flg22 and determines the specificity of flagellin perception. Plant Cell 18:465-476.

Crofts, A. J., Leborgne-Castel, N., Pesca, M., Vitale, A., and Denecke, J. 1998. BiP and calreticulin form an abundant complex that is independent of endoplasmic reticulum stress. Plant Cell 10:813-824.

Dangl, J. L., and Jones, J. D. G. 2001. Plant pathogens and integrated defence responses to infection. Nature 411:826-833.

Danon, A., Miersch, O., Felix, G., Camp, R. G., and Apel, K. 2005. Concurrent activation of cell death-regulating signaling pathways by singlet oxygen in Arabidopsis thaliana. Plant J. 41:68-80.

Deslandes, L., Olivier, J., Theulieres F. D. R., Hirsch, J., Feng, D. X., Bittner-Eddy, P., Beynon, J., and Marco, Y. 2002. Resistance to Ralstonia solanacearum in Arabidopsis thaliana is conferred by the recessive RRS1-R gene, a member of a novel family of resistance genes. Proc. Natl. Acad. Sci. U.S.A. 99:2404-2409.

Deslandes, L., Olivier, J., Peeters, N., Feng, D. X., Khounlotham, M., Boucher, C., Somssich, I., Genin, S. P., and Marco, Y. 2003. Physical interaction between RRS1-R, a protein conferring resistance to bacterial wilt, and PopP2, a type III effector targeted to the plant nucleus. Proc. Natl. Acad. Sci. U.S.A. 100:8024-8029.

Dixit, R., Cyr, R., and Gilroy, S. 2006. Using intrinsically fluorescent proteins for plant cell imaging. Plant J. 45:599-615.

Dong, X. 2004. NPR1, all things considered. Curr. Opin. Plant Biol. 7:547-522.

Ellis, J. G., Dodds, P. N., and Lawrence, G. J. 2007. Flax rust resistance gene specificity is based on direct resistance-avirulence protein interactions. Annu. Rev. Phytopathol. 45:289-306.

Feys, B. J., Moisan, L. J., Newman, M.-A., and Parker, J. E. 2001. Direct interaction between the Arabidopsis disease resistance signaling proteins, EDS1 and PAD4. EMBO (Eur. Mol. Biol. Organ.) J. 20:54005411 .

Feys, B. J., Wiermer, M., Bhat, R. A., Moisan, L. J., Medina-Escobar, N., Neu, C., Cabral, A., and Parker, J. E. 2005. Arabidopsis SENESCENCE-ASSOCIATED GENE101 stabilizes and signals within an ENHANCED DISEASE SUSCEPTIBILITY1 complex in plant innate immunity. Plant Cell 17:2601-2613.

Fu, Z. Q., Guo, M., Jeong, B.-R., Tian, F., Elthon, T. E., Cerny, R. L., Staiger, D., and Alfano, J. R. 2007. A type III effector ADP-ribosylates RNA-binding proteins and quells plant immunity. Nature 447:284-288.

Geisler, M., Axelsen, K. B., Harper, J. F., and Palmgren, M. G. 2000. Molecular aspects of higher plant P-type $\mathrm{Ca}^{2+}$-ATPases. Biochim. Biophys. Acta Biomembranes 1465:52-78.

Genoud, T., Buchala, A. J., Chua, N.-H., and Métraux, J.-P. 2002. Phytochrome signalling modulates the SA-perceptive pathway in Arabidopsis. Plant J. 31:87-95.

Gfeller, A., Dubugnon, L., Liechti, R., and Farmer, E. E. 2010. Jasmonate biochemical pathway. Sci. Signal. 3:cm3. Published online.

Gómez-Gómez, L., and Boller, T. 2000. FLS2: An LRR receptor-like kinase involved in the perception of the bacterial elicitor flagellin in Arabidopsis. Mol. Cell 5:1003.

Greenberg, J. T., Guo, A., Klessig, D. F., and Ausubel, F. M. 1994. Programmed cell death in plants: A pathogen-triggered response activated coordinately with multiple defense functions. Cell 77: 551-563.

Guttman, D. S., Vinatzer, B. A., Sarkar, S. F., Ranall, M. V., Kettler, G., and Greenberg, J. T. 2002. A functional screen for the type III (Hrp) secretome of the plant pathogen Pseudomonas syringae. Science 295:17221726.

Halterman, D., Zhou, F., Wei, F., Wise, R. P., and Schulze-Lefert, P. 2001. The MLA6 coiled-coil, NBS-LRR protein confers AvrMla6-dependent resistance specificity to Blumeria graminis f. sp. hordei in barley and wheat. Plant J. 25:335-348.

Halterman, D. A., and Wise, R. P. 2004. A single-amino acid substitution in the sixth leucine-rich repeat of barley MLA6 and MLA13 alleviates dependence on RAR1 for disease resistance signaling. Plant J. 38:215226.

Heath, M. C. 2000. Hypersensitive response-related death. Plant Mol. Biol. 44:321-334.

Hu, G., Yalpani, N., Briggs, S. P., and Johal, G. S. 1998. A porphyrin pathway impairment is responsible for the phenotype of a dominant disease lesion mimic mutant of maize. Plant Cell 10:1095-1106.

Hwang, C.-F., Bhakta, A. V., Truesdell, G. M., Pudlo, W. M., and Williamson, V. M. 2000. Evidence for a role of the $\mathrm{N}$ terminus and leucine-rich repeat region of the $M i$ gene product in regulation of localized cell death. Plant Cell 12:1319-1330.

Ishikawa, A., Okamoto, H., Iwasaki, Y., and Asahi, T. 2001. A deficiency of coproporphyrinogen III oxidase causes lesion formation in Arabidopsis. Plant J. 27:89-99.

Jelenska, J., Yao, N., Vinatzer, B. A., Wright, C. M., Brodsky, J. L., and Greenberg, J. T. 2007. A J domain virulence effector of Pseudomonas syringae remodels host chloroplasts and suppresses defenses. Curr. Biol. 17:499-508.

Jiang, C.-J., Shimono, M., Maeda, S., Inoue, H., Mori, M., Hasegawa, M., Sugano, S., and Takatsuji, H. 2009. Suppression of the rice fatty-acid desaturase gene OsSSI2 enhances resistance to blast and leaf blight diseases in rice. Mol. Plant-Microbe Interact. 22:820-829.

Jones, J. D. G., and Dangl, J. L. 2006. The plant immune system. Nature 444:323.

Kachroo, A., and Kachroo, P. 2009. Fatty acid-derived signals in plant defense. Annu. Rev. Phytopathol. 47:153-176.

Kachroo, A., Venugopal, S. C., Lapchyk, L., Falcone, D., Hildebrand, D. and Kachroo, P. 2004. Oleic acid levels regulated by glycerolipid metabolism modulate defense gene expression in Arabidopsis. Proc. Natl. Acad. Sci. U.S.A. 101:5152-5157.

Kachroo, A., Shanklin, J., Whittle, E., Lapchyk, L., Hildebrand, D., and Kachroo, P. 2007. The Arabidopsis stearoyl-acyl carrier protein-desaturase family and the contribution of leaf isoforms to oleic acid synthesis. Plant Mol. Biol. 63:257-271.

Kachroo, A., Fu, D.-Q., Havens, W., Navarre, D., Kachroo, P., and Ghabrial, S. A. 2008. An oleic acid-mediated pathway induces constitutive defense signaling and enhanced resistance to multiple pathogens in soybean. Mol. Plant-Microbe Interact. 21:564-575.

Kachroo, P., Shanklin, J., Shah, J., Whittle, E. J., and Klessig, D. F. 2001. A fatty acid desaturase modulates the activation of defense signaling pathways in plants. Proc. Natl. Acad. Sci. U.S.A. 98:9448-9453.

Kinkema, M., Fan, W., and Dong, X. 2000. Nuclear localization of NPR1 is required for activation of PR gene expression. Plant Cell 12:23392350

Kleizen, B., and Braakman, I. 2004. Protein folding and quality control in the endoplasmic reticulum. Curr. Opin. Cell Biol. 16:343-349.

Köster, M., Frahm, T., and Hauser, H. 2005. Nucleocytoplasmic shuttling revealed by FRAP and FLIP technologies. Curr. Opin. Biotechnol. $16: 28-34$

Kunze, G., Zipfel, C., Robatzek, S., Niehaus, K., Boller, T., and Felix, G. 2004. The $\mathrm{N}$ terminus of bacterial elongation factor Tu elicits innate immunity in Arabidopsis plants. Plant Cell 16:3496-3507.

Laloi, C., Stachowiak, M., Pers-Kamczyc, E., Warzych, E., Murgia, I., and Apel, K. 2007. Cross-talk between singlet oxygen- and hydrogen peroxide-dependent signaling of stress responses in Arabidopsis thaliana. Proc. Natl. Acad. Sci. U.S.A. 104:672-677.

Lee, K. P., Kim, C., Landgraf, F., and Apel, K. 2007. EXECUTER1- and EXECUTER2-dependent transfer of stress-related signals from the plastid to the nucleus of Arabidopsis thaliana. Proc. Natl. Acad. Sci. U.S.A. 104:10270-10275.

Li, J., Zhao-Hui, C., Batoux, M., Nekrasov, V., Roux, M., Chinchilla, D., Zipfel, C., and Jones, J. D. G. 2009. Specific ER quality control components required for biogenesis of the plant innate immune receptor EFR. Proc. Natl. Acad. Sci. U.S.A. 106:15973-15978.

Li, X., Clarke, J. D., Zhang, Y., and Dong, X. 2001. Activation of an EDS1-mediated $R$-gene pathway in the snc1 mutant leads to constitutive, NPR1-independent pathogen resistance. Mol. Plant-Microbe Interact. 14:1131-1139.

Liu, J., and Coaker, G. 2008. Nuclear trafficking during plant innate immunity. Mol. Plant 1:411-422.

Liu, Y., Ren, D., Pike, S., Pallardy, S., Gassmann, W., and Zhang, S. 2007. Chloroplast-generated reactive oxygen species are involved in hypersensitive response-like cell death mediated by a mitogen-activated protein kinase cascade. Plant J. 51:941-954.

Lorrain, S., Vailleau, F., Balague, C., and Roby, D. 2003. Lesion mimic mutants: Keys for deciphering cell death and defense pathways in plants? Trends Plant Sci. 8:263-271.

Lu, X., Tintor, N., Mentzel, T., Kombrink, E., Boller, T., Robatzek, S. Schulze-Lefert, P., and Saijo, Y. 2009. Uncoupling of sustained MAMP receptor signaling from early outputs in an Arabidopsis endoplasmic reticulum glucosidase II allele. Proc. Natl. Acad. Sci. U.S.A. 106:2252222527.

Ma, W., and Berkowitz, G. A. 2007. The grateful dead: Calcium and cell death in plant innate immunity. Cell. Microbiol. 9:2571-2585.

Maleck, K., Levine, A., Eulgem, T., Morgan, A., Schmid, J., Lawton, K. A., Dangl, J. L., and Dietrich, R. A. 2000. The transcriptome of Arabi 
dopsis thaliana during systemic acquired resistance. Nat. Genet. 26:403-410.

Matarasso, N., Schuster, S., and Avni, A. 2005. A novel plant cysteine protease has a dual function as a regulator of 1-aminocyclopropane-1-carboxylic acid synthase gene expression. Plant Cell 17:1205-1216.

Mateo, A., Muhlenbock, P., Rusterucci, C., Chang, C. C.-C., Miszalski, Z., Karpinska, B., Parker, J. E., Mullineaux, P. M., and Karpinski, S. 2004. LESION SIMULATING DISEASE 1 is required for acclimation to conditions that promote excess excitation energy. Plant Physiol. 136:2818-2830.

Meier, I. 2007. Composition of the plant nuclear envelope: Theme and variations. J. Exp. Bot. 58:27-34.

Mesaeli, N., Nakamura, K., Zvaritch, E., Dickie, P., Dziak, E., Krause, K.H., Opas, M., MacLennan, D. H., and Michalak, M. 1999. Calreticulin is essential for cardiac development. J. Cell Biol. 144:857-868.

Mestre, P., and Baulcombe, D. C. 2006. Elicitor-mediated oligomerization of the tobacco N disease resistance protein. Plant Cell 18:491-501.

Miya, A., Albert, P., Shinya, T., Desaki, Y., Ichimura, K., Shirasu, K. Narusaka, Y., Kawakami, N., Kaku, H., and Shibuya, N. 2007. CERK1, a LysM receptor kinase, is essential for chitin elicitor signaling in Arabidopsis. Proc. Natl. Acad. Sci. U.S.A. 104:19613-19618.

Mochizuki, N., Tanaka, R., Tanaka, A., Masuda, T., and Nagatani, A. 2008 The steady-state level of Mg-protoporphyrin IX is not a determinant of plastid-to-nucleus signaling in Arabidopsis. Proc. Natl. Acad. Sci. U.S.A. 105:15184-15189.

Mou, Z., Fan, W., and Dong, X. 2003. Inducers of plant systemic acquired resistance regulate NPR1 function through redox changes. Cell 113:935-944.

Moulin, M., McCormac, A. C., Terry, M. J., and Smith, A. G. 2008 Tetrapyrrole profiling in Arabidopsis seedlings reveals that retrograde plastid nuclear signaling is not due to Mg-protoporphyrin IX accumulation. Proc. Natl. Acad. Sci. U.S.A. 105:15178-15183.

Nekrasov, V., Li, J., Batoux, M., Roux, M., Chu, Z.-H., Lacombe, S., Rougon, A., Bittel, P., Kiss-Papp, M., Chinchilla, D., van Esse, H. P., Jorda, L., Schwessinger, B., Nicaise, V., Thomma, B. P. H. J., Molina, A., Jones, J. D. G., and Zipfel, C. 2009. Control of the pattern-recognition receptor EFR by an ER protein complex in plant immunity. EMBO (Eur. Mol. Biol. Organ.) J. 28:3428-3438.

Nixon, P. J., Barker, M., Boehm, M., de Vries, R., and Komenda, J. 2005. FtsH-mediated repair of the photosystem II complex in response to light stress. J. Exp. Bot. 56:357-363.

Noutoshi, Y., Ito, T., Seki, M., Nakashita, H., Yoshida, S., Marco, Y., Shirasu, K., and Shinozaki, K. 2005. A single amino acid insertion in the WRKY domain of the Arabidopsis TIR-NBS-LRR-WRKY-type disease resistance protein SLH1 (sensitive to low humidity 1) causes activation of defense responses and hypersensitive cell death. Plant J. 43:873-888.

Oelmüller, R., and Mohr, H. 1986. Photooxidative destruction of chloroplasts and its consequences for expression of nuclear genes. Planta 167:106-113.

Oliver, J., Castro, A., Gaggero, C., Cascón, T., Schmelz, E., Castresana, C., and Ponce de León, I. 2009. Pythium infection activates conserved plant defense responses in mosses. Planta 230:569-579.

op den Camp, R. G. L., Przybyla, D., Ochsenbein, C., Laloi, C., Kim, C., Danon, A., Wagner, D., Hideg, E., Gobel, C., Feussner, I., Nater, M., and Apel, K. 2003. Rapid induction of distinct stress responses after the release of singlet oxygen in Arabidopsis. Plant Cell 15:2320-2332.

Orgil, U., Araki, H., Tangchaiburana, S., Berkey, R., and Xiao, S. 2007. Intraspecific genetic variations, fitness cost and benefit of RPW8, a disease resistance locus in Arabidopsis thaliana. Genetics 176:2317-2333.

Palma, K., Zhang, Y., and Li, X. 2005. An importin [alpha] homolog, MOS6, plays an important role in plant innate immunity. Curr. Biol. 15:1129-1135.

Park, C.-J., Bart, R., Chern, M., Canlas, P. E., Bai, W., and Ronald, P. C. 2010. Overexpression of the endoplasmic reticulum chaperone BiP3 regulates XA21-mediated innate immunity in rice. PLoS ONE 5:e9262. Published online

Pattison, R. J., and Amtmann, A. 2009. N-glycan production in the endoplasmic reticulum of plants. Trends Plant Sci. 14:92-99.

Postel, S., and Kemmerling, B. 2009. Plant systems for recognition of pathogen-associated molecular patterns. Semin. Cell Dev. Biol. 20:1025-1031.

Pruinska, A., Tanner, G., Anders, I., Roca, M., and Hãrtensteiner, S. 2003. Chlorophyll breakdown: Pheophorbide a oxygenase is a Rieske-type iron-sulfur protein, encoded by the accelerated cell death 1 gene. Proc. Natl. Acad. Sci. U.S.A. 100:15259-15264.

Pruzinska, A., Tanner, G., Aubry, S., Anders, I., Moser, S., Muller, T. Ongania, K. H., Krautler, B., Youn, J. Y., Liljegren, S. J., and Hörtensteiner, S. 2005. Chlorophyll breakdown in senescent Arabidopsis leaves. Characterization of chlorophyll catabolites and of chloro- phyll catabolic enzymes involved in the degreening reaction. Plant Physiol. 139:52-63

Reddy, P., Sparvoli, A., Fagioli, C., Fassina, G., and Sitia, R. 1996. Formation of reversible disulfide bonds with the protein matrix of the endoplasmic reticulum correlates with the retention of unassembled Ig light chains. EMBO (Eur. Mol. Biol. Organ.) J. 15:2077-2085.

Reiko, U. 2009. The endoplasmic reticulum stress signaling pathways in plants. BioFactors 35:326-331.

Richardson, C. E., Kooistra, T., and Kim, D. H. 2010. An essential role for $\mathrm{XBP}-1$ in host protection against immune activation in $C$. elegans. Nature 463:1092-1095

Sacco, M. A., Mansoor, S., and Moffett, P. 2007. A RanGAP protein physically interacts with the NB-LRR protein $\mathrm{Rx}$, and is required for $\mathrm{Rx}$ mediated viral resistance. Plant J. 52:82-93.

Saijo, Y., Tintor, N., Lu, X., Rauf, P., Pajerowska-Mukhtar, K., Haweker, H., Dong, X., Robatzek, S., and Schulze-Lefert, P. 2009. Receptor quality control in the endoplasmic reticulum for plant innate immunity. EMBO (Eur. Mol. Biol. Organ.) J. 28:3439.

Seo, S., Okamoto, M., Iwai, T., Iwano, M., Fukui, K., Isogai, A., Nakajima, N., and Ohashi, Y. 2000. Reduced levels of chloroplast FtsH protein in Tobacco mosaic virus-infected tobacco leaves accelerate the hypersensitive reaction. Plant Cell 12:917-932.

Shen, Q.-H., Zhou, F., Bieri, S., Haizel, T., Shirasu, K., and Schulze-Lefert, P. 2003. Recognition specificity and RAR1/SGT1 dependence in barley Mla disease resistance genes to the powdery mildew fungus. Plant Cell 15:732-744.

Shen, Q.-H., Saijo, Y., Mauch, S., Biskup, C., Bieri, S., Keller, B., Seki, H., Ulker, B., Somssich, I. E., and Schulze-Lefert, P. 2007. Nuclear activity of MLA immune receptors links isolate-specific and basal disease-resistance responses. Science 315:1098-1103.

Shirasu, K. 2009. The HSP90-SGT1 chaperone complex for NLR immune sensors. Annu. Rev. Plant Biol. 60:139-164.

Spoel, S. H., Koornneef, A., Claessens, S. M. C., Korzelius, J. P., Van Pelt, J. A., Mueller, M. J., Buchala, A. J., Metraux, J.-P., Brown, R., Kazan, K., Van Loon, L. C., Dong, X., and Pieterse, C. M. J. 2003. NPR1 modulates cross-talk between salicylate- and jasmonate-dependent defense pathways through a novel function in the cytosol. Plant Cell 15:760-770.

Spoel, S. H., Mou, Z., Tada, Y., Spivey, N. W., Genschik, P., and Dong, X. 2009. Proteasome-mediated turnover of the transcription coactivator NPR1 plays dual roles in regulating plant immunity. Cell 137:860-872.

Takahashi, M., and Asada, K. 1988. Superoxide production in aprotic interior of chloroplast thylakoids. Arch. Biochem. Biophys. 267:714-722.

Tameling, W. I. L., and Baulcombe, D. C. 2007. Physical association of the NB-LRR resistance protein Rx with a Ran GTPase-activating protein is required for extreme resistance to Potato virus $X$. Plant Cell 19:1682-1694.

Tao, Y., Xie, Z., Chen, W., Glazebrook, J., Chang, H.-S., Han, B., Zhu, T., Zou, G., and Katagiri, F. 2003. Quantitative nature of Arabidopsis responses during compatible and incompatible interactions with the bacterial pathogen Pseudomonas syringae. Plant Cell 15:317-330.

Torres, M. A., and Dangl, J. L. 2005. Functions of the respiratory burst oxidase in biotic interactions, abiotic stress and development. Curr. Opin. Plant Biol. 8:397.

Torres, M. A., Dangl, J. L., and Jones, J. D. G. 2002. Arabidopsis gp91phox homologues AtrbohD and AtrbohF are required for accumulation of reactive oxygen intermediates in the plant defense response. Proc. Natl. Acad. Sci. U.S.A. 99:517-522.

Torres, M. A., Jones, J. D. G., and Dangl, J. L. 2006. Reactive oxygen species signaling in response to pathogens. Plant Physiol. 141:373-378.

Vembar, S. S., and Brodsky, J. L. 2008. One step at a time: Endoplasmic reticulum-associated degradation. Nat. Rev. Mol. Cell Biol. 9:944-957.

Vitale, A., and Boston, R. S. 2008. Endoplasmic reticulum quality control and the unfolded protein response: Insights from plants. Traffic 9:15811588 .

Vlot, A. C., Dempsey, D. M. A., and Klessig, D. F. 2009. Salicylic acid, a multifaceted hormone to combat disease. Annu. Rev. Phytopathol. 47:177-206.

Wagner, D., Przybyla, D., op den Camp, R., Kim, C., Landgraf, F., Lee, K. P., Wursch, M., Laloi, C., Nater, M., Hideg, E., and Apel, K. 2004. The genetic basis of singlet oxygen-induced stress responses of Arabidopsis thaliana. Science 306:1183-1185.

Wang, D., Weaver, N. D., Kesarwani, M., and Dong, X. 2005. Induction of protein secretory pathway is required for systemic acquired resistance. Science 308:1036-1040.

Wang, D., Amornsiripanitch, N., and Dong, X. 2006. A genomic approach to identify regulatory nodes in the transcriptional network of systemic acquired resistance in plants. PLoS Pathog. 2:e123. Published online.

Wang, Y., Bao, Z., Zhu, Y., and Hua, J. 2009. Analysis of temperature modulation of plant defense against biotrophic microbes. Mol. PlantMicrobe Interact. 22:498-506. 
Wasternack, C. 2007. Jasmonates: An update on biosynthesis, signal transduction and action in plant stress response, growth and development. Ann. Bot. 100:681-697.

Weber, H. 2002. Fatty acid-derived signals in plants. Trends Plant Sci. 7:217-224.

Whitham, S., McCormick, S., and Baker, B. 1996. The N gene of tobacco confers resistance to tobacco mosaic virus in transgenic tomato. Proc. Natl. Acad. Sci. U.S.A. 93:8776-8781.

Wiermer, M., Feys, B. J., and Parker, J. E. 2005. Plant immunity: The EDS1 regulatory node. Curr. Opin. Plant Biol. 8:383.

Wildermuth, M. C., Dewdney, J., Wu, G., and Ausubel, F. M. 2001. Isochorismate synthase is required to synthesize salicylic acid for plan defence. Nature 414:562-565.

Williams, D. B. 2006. Beyond lectins: The calnexin/calreticulin chaperone system of the endoplasmic reticulum. J. Cell Sci. 119:615-623.

Wirthmueller, L., Zhang, Y., Jones, J. D. G., and Parker, J. E. 2007. Nuclear accumulation of the Arabidopsis immune receptor RPS4 is necessary for triggering EDS1-dependent defense. Curr. Biol. 17:20232029.

Woodson, J. D., and Chory, J. 2008. Coordination of gene expression between organellar and nuclear genomes. Nat. Rev. Genet. 9:383-395.

Yaeno, T., Matsuda, O., and Iba, K. 2004. Role of chloroplast trienoic fatty acids in plant disease defense responses. Plant J. 40:931-941.

Yang, S., and Hua, J. 2004. A haplotype-specific resistance gene regulated by BONZAI1 mediates temperature-dependent growth control in Arabidopsis. Plant Cell 16:1060-1071.

Yang, Y., Liu, B., Dai, J., Srivastava, P. K., Zammit, D. J., Lefrançois, L., and $\mathrm{Li}, \mathrm{Z}$. 2007. Heat shock protein gp96 is a master chaperone for Toll-like receptors and is important in the innate function of macrophages. Immunity 26:215-226.

Yao, N., and Greenberg, J. T. 2006. Arabidopsis ACCELERATED CELL DEATH2 modulates programmed cell death. Plant Cell 18:397-411.

Zhang, X., Chen, S., and Mou, Z. 2010. Nuclear localization of NPR1 is required for regulation of salicylate tolerance, isochorismate synthase 1 expression and salicylate accumulation in Arabidopsis. J. Plant Physiol. 167:144-148.
Zhang, Y., and Li, X. 2005. A putative nucleoporin 96 is required for both basal defense and constitutive resistance responses mediated by suppressor of npr1-1,constitutive 1. Plant Cell 17:1306-1316.

Zhang, Y., Fan, W., Kinkema, M., Li, X., and Dong, X. 1999. Interaction of NPR1 with basic leucine zipper protein transcription factors that bind sequences required for salicylic acid induction of the PR-1 gene. Proc. Natl. Acad. Sci. U.S.A. 96:6523-6528.

Zhang, Y., Goritschnig, S., Dong, X., and Li, X. 2003. A gain-of-function mutation in a plant disease resistance gene leads to constitutive activation of downstream signal transduction pathways in suppressor of npr11, constitutive 1. Plant Cell 15:2636-2646.

Zhou, F., Kurth, J., Wei, F., Elliott, C., Vale, G., Yahiaoui, N., Keller, B., Somerville, S., Wise, R., and Schulze-Lefert, P. 2001. Cell-autonomous expression of barley Mla1 confers race-specific resistance to the powdery mildew fungus via a Rar1-independent signaling pathway. Plant Cell 13:337-350.

Zhu, X., Caplan, J., Mamillapalli, P., Czymmek, K., and Dinesh-Kumar, S. P. 2010. Function of endoplasmic reticulum calcium ATPase in innate immunity-mediated programmed cell death. EMBO (Eur. Mol. Biol. Organ.) J. 29:1007-1018.

Zhu, Y., Qian, W., and Hua, J. 2010. Temperature modulates plant defense responses through NB-LRR proteins. PLoS Pathog. 6:e1000844. Published online.

Zipfel, C. 2008. Pattern-recognition receptors in plant innate immunity. Curr. Opin. Immunol. 20:10-16.

Zipfel, C. 2009. Early molecular events in PAMP-triggered immunity. Curr. Opin. Plant Biol. 12:414-420.

Zipfel, C., Kunze, G., Chinchilla, D., Caniard, A., Jones, J. D. G., Boller, T., and Felix, G. 2006. Perception of the bacterial PAMP EF-Tu by the receptor EFR restricts Agrobacterium-mediated transformation. Cell 125:749-760.

Zurbriggen, M. D., Carrillo, N., Tognetti, V. B., Melzer, M., Peisker, M., Hause, B., and Hajirezaei, M. R. 2009. Chloroplast-generated reactive oxygen species play a major role in localized cell death during the nonhost interaction between tobacco and Xanthomonas campestris pv. vesicatoria. Plant J. 60:962-973. 